\title{
О СТАНОВЛЕНИИ РОССИЙСКОГО ГОСУДАРСТВА В ТРУДАХ Б.Н. ЧИЧЕРИНА
}

\section{ON THE FORMATION OF THE RUSSIAN STATE IN THE WORKS OF B.N. CHICHERIN}

\section{S. Volk-Leonovich}

Summary. The questions of the genesis of the state (in general) and the Russian state (in particular) were most thoroughly developed in the works of Boris Nikolayevich Chicherin. According to the terminology of B.N. Chicherin, the state is the result of the evolution of simpler social structures, unions. At the same time, for the emergence of the idea of the state, B.N. Chicherin identified several conditions: conquest (bringing the conquered to submission), religious teaching, and the natural evolution of social structures. In addition, scientists have identified three periods that the society passes on the way to the formation of the state. The first stage of this process is occupied by the family (gradually transforming into the genus), as the primary social structure, implicitly containing the characteristics of all future social structures, including the state. Further, the development of the family is associated with the expansion of the family into a genus, based also on kinship ties, but a broader blood relationship. Finally, a further increase in the population leads to the emergence of a new, more complex social structure - the tribe. However, in the tribe, social differentiation increases even more than in the clan. Thus, the tribal organization of society is the forerunner of the state. And one of the important factors in the formation of the Russian state, B.N. Chicherin calls "the invasion of Western squads, mainly Varangians". At the same time, the further development of statehood is associated with the enlargement of the possessions of individual princes-patrimony, based primarily on the instinct of self-preservation.

Keywords: state genesis, conquests, evolution of social structures, periods of state formation, family, tribe, patrimonial princes, social differentiation.
Волк-Леонович Станислав Олегович

Нижегородская академия Министерства внутренних дел Российской Федерации ejiwolf2006@rambler.ru

Аннотация. Вопросы генезиса государства (в целом) и русского государства (в частности) наиболее тщательным образом были разработаны в трудах Бориса Николаевича Чичерина. Согласно терминологии Б.Н. Чичерина, государство является результатом эволюции более простых социальных структур, союзов. При этом для возникновения идеи государства Б.Н. Чичерин выделял несколько условий: завоевание (приведение к покорности побежденных), религиозное учение, естественная эволюция социальных структур. Кроме того, ученым выделено три периода, которые проходит общество на пути к становлению государства. Первую ступень этого процесса занимает семья, (постепенно трансформирующаяся в род), как первичная социальная структура, имплицитно содержащая признаки всех будущих социальных структур, в том числе и государства. Далее развитие семьи связано с разрастанием семьи в род, основанным также на родственных связях, но более широким кровным родством. И, наконец, дальнейшее увеличение численности народонаселения приводит к возникновению новой более сложной социальной структуры - племени. Однако, в племени в еще большей степени, по сравнению с родом, возрастает социальная дифференциация. Таким образом, племенная организация общества - это предтеча государства. А одним из важных факторов в становлении русского государства Б.Н. Чичерин называет «нашествие западных дружин, преимущественно Варягов». При этом, дальнейшее развитие государственности связано с укрупнением владений отдельных князей-вотчинников, основанном, прежде всего, на инстинкте самосохранения.

Ключевые слова: генезис государства, завоевания, эволюция социальных структур, периоды становления государства, семья, племя, князья-вотчинники, социальная дифференциация.

Условие, которое необходимо для эволюции социальных структур, развития политического сознания, формирования идеи государства, в силу которой существующая законная власть формирует организацию, тождественную идеи государства, для возникновения идеи государства Б.Н. Чичерин выделяет следующие условия: завоевание (приведение к покорности побежденных), религиозное учение, естественная эволюция социальных структур, обусловленная изменением потребностей, посредством трансформации форм 
частного права в публичное. «Таким образом, во всех этих способах законная власть, патриархальная, гражданская или религиозная, устанавливает новый порядок во имя высшей идеи» [3, с. 101].

Б.Н. Чичериным предлагается четко выстроенная теория эволюции социальных структур. Применяя эту схему к истории России, ученый выделяет три периода, которые проходит общество на пути к становлению государства. Первую ступень этого процесса занимает семья, постепенно трансформирующаяся в род, в семье социальная связь между людьми основывается на кровном родстве, это, по сути, большая патриархальная семья. Эта первичная социальная структура имплицитно содержит признаки всех будущих социальных структур, в том числе и государства. В этой форме мы встречаем не механическое объединение лиц, а единый союз, сложную социальную организацию, в которой место индивида детерминировано природой этой организации и определяет его статус. Сложная структура родовой общности определяет потребность в управлении, что определяет формирование властной структуры и отношений власти-подчинения. Такой структурой выступает патриархия, власть отца. Однако такой союз не является устойчивым и не может существовать как целостная структура более или менее длительное время. Это временный союз, так как, взрослые дети могут уйти и образовать свои собственные семьи, со смертью домовладыки такой союз прекращается [5, с. 7]. Отсюда Б.Н. Чичерин делает вывод, что такой союз не может реализовать потребности в длительном существовании индивидов и может обеспечивать потребности людей лишь на ранней ступени развития.

Дальнейшее развитие семьи связано с разрастанием семьи в род. Основанным также на родственных связях, но более широким кровным родством. Члены такого союза подвластны общему родоначальнику патриарху. По смерти патриарха в отличие от семьи род не исчезает, здесь уже формируется институт транзита власти, власть переходит старейшему в роду. Патриарх в роду эмулирует по отношению ко всем членам рода не в зависимости от фактического родства отношения отца. Таким образом, это уже не просто естественный союз как семья, а социальная структура с элементами искусственности, фикции отцовской власти. Усложняется и социальная структура, ведь род включает в себя и других патриархов, а также младших и старших членов семьи, статус которых определяется близостью к фигуре родоначальника. Усложняется и организация управления, отцы семейств могут сами принимать участие в общем управлении [3, с. 162]. На этом этапе появляются различные формы управления. Так как власть уже более не производна от самой природы, она нуждается в легитимации. И если первоначально носитель верховной власти определяется фактическим старшинством, то в родовой организации понятие старшинства подвергается трансформации. В поздний период старшинство определяется линейным принципом, вследствие этого, от власти устраняются потомки младших в семье, такое урегулирование транзита власти вызывает кризис в случае пресечения линии. Подобный кризис может привести к легитимации власти посредством выборов, что приводит к возможности формирования двух форм управления: аристократического или демократического, в зависимости от состава выборщиков.

Дальнейшее увеличение численности народонаселения приводит к возникновению новой более сложной социальной структуры - племени. Разделение славян, обитающих на территории будущего русского государства, на племена предполагает наличие естественной, родовой связи между людьми. Народное единство основывается на союзе племенном, все гражданские отношения вытекают из отношений естественных или патриархальных. С племенем неразлучен и род, это меньшая его единица. В племени в еще большей степени, по сравнению с родом, возрастает социальная дифференциация: появляется нобилитет и зависимое население, хотя сохраняются и сходные черты, так племя подобно роду в своей основе имеет восхождение к общему предку, т.е. всю ту же основанную на родстве связь и включает в себя патриархальные семьи и роды. Институт патриарха в племени трансформируется в институт княжеской власти. В отличие от родовой организации в племени возрастает потребность в формальных нормах, так как отношения уже не могут регулироваться внутрисемейными обыкновениями в силу возрастания отчужденности индивидов из-за возрастания населения. «Закон, пишет Б.Н. Чичерин, получает уже форму народного обычая, постоянного и непреложного» [3, с. 162]. Власть Князя урегулирована нормами обычного права, в отличие от предыдущих организационных форм. Он связан и отношениями к родоначальникам, или к старейшинам, которые сами являются обладателями патриархальной власти. При князе обыкновенно существует совет старейшин. Здесь может существовать и народное собрание, которое, однако, играет более пассивную роль: оно выслушивает старейшин и выражает одобрение.

Особенностью родовой организации в Древнерусском государстве выступает общая собственность на землю, которая ежегодно перераспределяется между членами общины. Это получает подтверждение и в русской истории, где род Рюриковичей выступает в роли коллективного сюзерена. Б.Н. Чичерин отмечает, что пережитки родовой собственности сохранились в выкупе родовых имуществ [5, с. 7].

Таким образом, племенная организация общества это предтеча государства, но только предтеча, ибо госу- 
дарство не может быть основано на кровном родстве, здесь, по сути, воспроизводится мысль К.Д. Кавелина, о том, что в основе государства лежит духовное единство индивидов. Более-менее длительное существование племенной организации возможно лишь при неизменности геополитических условий, в которых существует подобная организация общества [5, с. 7].

Б.Н. Чичерин отмечает, что патриархальная община существует в неизменном виде лишь при условии неизменности статуса индивида в общине, при неизменности отношений, которые воспроизводятся в течение длительного времени [5, с. 24].

Но подобный исход не был уготован племенам, которым предстояло стать русским народом. Одним из важных факторов в становлении русского государства Б.Н.Чичерин называет «нашествие западных дружин, преимущественно Варягов». «Ход русской истории,- пишет Чичерин в этой связи,- представляет замечательную параллель с историей Запада. И здесь, и там общественное развитие начинается с появления германской дружины, подчиняющей себе туземцев. И здесь, и там за первым дружинным периодом следует эпоха развития вотчинного начала, когда общество дробится на множество отдельных союзов, основанных на праве собственности [4, с. 338]. Дружина - это социальная структура, в которой господствуют отношения, совершенно противоположные родственно-общинным, членов дружины объединяют индивидуальные цели, совпадающие на определенный момент времени, что обуславливает заключение союза между ними, который основан на доброй воле каждого из них. Дружину составляли лица, статус которых определялся воинской силой и отвагой [5, с. 25].

В качестве свидетельства подобной трансформации Б.Н. Чичерин приводит нормы пространной редакции Русской Правды, регламентирующие порядок наследования, в частности ст. 90, 91 предусматривающие, что в случае смерти боярина или дружинника в отсутствие сыновей к наследству призываются дочери, в случае смерти смерда, его имущество переходит князю. Это еще один важный индикатор развития социальной структуры, а именно возникновение права частной собственности, что, по мнению Б.Н. Чичерина, служит признаком признания за личностью обособленного статуса. При этом, мы видим свидетельства эксплуатации низших слоев населения, но не родовой или семейной организацией, а именно князем главы дружины - представителем нового начала [5, с. 8], которое проявляется в собственности князя на землю, право на наследование после умерших членов общины. Князь становится верховным землевладельцем в границах, не совпадающих с территорией прежних общин, как глава гражданского общества. Следовательно, князь - это прин- ципиально новый институт власти, сначала основанный на праве владения землей, а впоследствии трансформировавшийся в публичную, государственную власть [5, с. 9]. Роль князя в процессе формирования государства как владельца земли, приобретает решающее значение, в особенности после Любечского съезда. Земля приобретает черты вотчины. Целями князей становится территориальная экспансия, расширение и укрепление своих владений, а сами они становятся вотчинниками. Собственность на землю становится основным, центральным пунктом в генезисе государства.

Исключение составляют только Новгород и Псков. В Новгородском и Псковском княжествах в большей степени сохраняется социальная организация предыдущего периода, прежде всего свободная община, Б.Н. Чичерин отмечает, что эта свободная община претерпевает определенную трансформацию: из родовой она превращается договорную. Таким образом, данный период в процессе генеза государства характеризуется возникновением и господством в политической жизни двух элементов, договорного и частновладельческого. Управленческие структуры родового периода (вече и советы старейшин) вытесняются институтом княжеской власти. Повсеместно кровные отношения в общине вытесняются договорными, соседскими, основанными на добровольном согласии, подобно дружине. В это период говорить о государстве еще рано, отношения характеризуются частным характером, важный признак государства «общее благо» в этот период еще не сформировалась, нельзя считать государством и Новгород с Псковом. Эти княжества выступают в качестве корпоративных собственников, по своей сути являясь коллективным вотчинником, «и все различие между ним и другими областями состояло в том, что там верховным вотчинником был князь, здесь же это место принадлежало союзу свободных лиц» $[5$, с. 10].

Таким образом, в это период мы можем говорить о двух формах генеза государства, во многом схожих, отличавшихся скорее формой, нежели содержанием, это вотчина, под которой Б.Н. Чичерин понимает форму гражданского союза, основанной на принадлежности земли князю, как собственнику.

Причиной возникновения вотчины является завоевание территорий дружинами. Во главе дружины стоит князь. Отношение между князем и дружинниками носят договорной характер и, таким образом, дружина является первой формой частного, или гражданского, союза, возникающего по свободной воле лиц, для достижений общих целей лиц, составлявших подобный союз. Подчинение князю зиждется на осознании того, что данное лицо ведет союз к достижению общей цели, следовательно, добровольно. Ключевой фигурой этого 
периода является автономная личность, наделенная свободой, в отличие от человека предыдущего периода, не мыслившего себя иначе как членом рода. Индивид выступает полноправным субъектом частноправовых отношений и членом гражданского общества. Такое состояние не исключает имущественного неравенства и рабского состояния побежденных.

Исключением не является и ядро будущего Русского государства - Великое Московское княжество. Анализируя духовные и договорные грамоты великих и удельных князей, Б.Н. Чичерин убедительно показывает на примере духовной грамоты Ивана Калиты [5, с. 240].

Б.Н. Чичерин подобно Ф.Л. Морошкину указывает, что в этот период появляются отдельные признаки государства, а именно в виде внешней власти над покоренными народами [3, с. 163]. Князь, как глава дружины, становится верховным собственником всей земли, дружинники приобретают частную собственность, которая вступает в различные отношения к верховной собственности князя. Отношения собственности на землю в этот период выступают основой этого нового общественного устройства [3, с. 120].

Особенностью генеза государства в России является неопределенность права собственности на землю. Земли, не находившиеся в частной собственности, а принадлежавшие свободным, так называемым черным, крестьянам, считались только их владением, а землею великого князя, не как государя, ибо государственная власть одинаково распространяется на всех, а именно как собственника, в отличие от прав его на частные вотчины.

Еще один фактор особенности генеза российского государства - географический, из-за протяженности территорий дружинники не превращаются в классических феодалов, сохраняя договорные отношения с князем и как следствие право выбора себе князя, высокая мобильность населения препятствовала созданию государства [4, с. 340].

Подводя итог рассмотрения этого периода в работах Б.Н. Чичерина, следует отметить признаки, которые позволяют сделать вывод лишь о становлении государства. Данный период в Российской империи характеризуется господством отдельных частных лиц, власть которых не урегулирована нормами, обеспечивающими государственный порядок. Еще одним важным индикатором отсутствия государства является отношение собственности, вотчина для князей - это не государственная территория, а земельный участок, находящийся в собственности, а люди, которые его на- селяют - не более чем арендаторы в нашем понимании этого слова, т.е. Киевская Русь, не более чем союз землевладельцев, корпорация по совместной эксплуатации природных и людских ресурсов. Это подтверждается фактическими и юридическими действиями князей, такими как раздел земли между наследниками, захват земли и владение по праву оккупации, передача отдельных территорий во владение другим лицам, передача земли в прокорм $[5,6]$.

Государство может распасться на отдельные территории вследствие определенных условий, территория государства может состоять из нескольких частей, может состоять из нескольких отдельных государств, образующих одно целое. Но в Древнерусском государстве дробление уделов определяется внутренним постоянным законом, что свидетельствует об отсутствии такого важного признака как нераздельности государственной территории, что указывает на отсутствие на Руси государства $[3,5]$.

Таким образом, Б.Н. Чичерин делает вывод, что князья не более чем простые собственники, а не представители публичной власти, отношение носят ярко выраженный частный, а не публичный характер, земля - это не государственная территория, а территория частного собственника, народа как такового нет, есть люди, находящиеся с князьями и между собой в договорных отношениях. Сами князья строят отношения между собой и великим князем в соответствии с договором. Б.Н. Чичерин делает вывод, что такие отношения предполагают, что контрагенты независимы друг от друга, а, следовательно, не находятся в отношениях власти-подчинения, и далее остается лишь сделать вывод, что власть великого князя не носит государственный характер, а сам он не государь, а удельные князья по отношению к нему не являются подданными, так же, как и люди, населяющие землю уделов по отношению к удельным князьям. Следует обратить внимание и на содержание договоров, где в обязанности князей входит осуществление службы в отношении великого князя. Также в договоре присутствуют юридические формулы, которые, по мнению Б.Н. Чичерина, не носят характера публичного отношения, а являются ярко выраженными отношениями частноправового характера, заверяемые при этом посредством принесения личной клятвы на кресте «крестоцелованием». Это указывает на отсутствие таких признаков как верховная власть и народ. В целом, заключает он, «это был порядок самый противоположный государственному» [5, с. 336].

Отношение в вольной общине подобно вотчине не носят публичный характер, а являются частноправовыми. Вместо князя-вотчинника здесь выступает корпорация, «союз свободных людей, живущих вместе 
и состоящих друг с другом в договорных отношениях» [5, с. 336]. Генез этой формы обусловлен наличием у общины достаточных ресурсов, чтобы в условиях господства частного права противостоять притязаниям князей и дружинников. Независимость вольной общины не безусловна. Идея государства, согласно Б.Н. Чичерину, предполагает понятие о самостоятельности, потому что в государстве существует верховная власть. Природа вольной общины, это природа частного союза, подобного дружине, который становится самостоятельным вследствие отсутствия в обществе государственных начал. Будучи корпорацией, а не государством, община выступает субъектом прав, обязанностей и, наконец, власти. Община имеет свои земли, которыми она владеет, так же как князь владеет своей вотчиной. В истории Российского государства эта форма не реализовалась, уступив натиску московских князей.

Дальнейшее развитие государственности связано с укрупнением владений отдельных князей-вотчинников, основанном, прежде всего, на инстинкте самосохранения, «чтобы остаться целым и невредимым, чтобы сохранить свое место, каждый князь должен был необходимо стремиться к умножению своей силы, к увеличению своих владений» [5, с. 336]. Такая политика, в силу своей затратности, требует большее количество материальных ресурсов, более высокую степень концентрации власти и, как следствие, необходимость подчинения всего населения княжества. Именно в этом, по мнению Б.Н. Чичерина, скрывается «зародыш будущего государственного подданства» [5, с. 336]. Необходимо было лишь преодолеть нормы частного права предыдущего периода, которые препятствовали кумулятивному процессу формирования территориального могущества в руках одного лица. Ко времени правления Ивана III становится очевидным, что могущество нельзя сохранить иначе, как усилив одного наследника за счет других. На смену господству частноправовых отношений приходят публичные; социальная структура обретает черты, характерные для государства и единодержавия, выражающегося в целостности социума, земли и верховной власти. Этот тезис обосновывает- ся содержанием духовной грамоты Ивана III, предусматривавшей территориальный приоритет старшего сына по сравнению с младшими детьми. В результате, власть великого Московского князя возрастает, обеспеченная материальными ресурсами, что приводит удельных князей в зависимое отношение. В этом факте Б.Н. Чичерин усматривает тенденцию возведения частного права к публичному, посредством усиления одного наследника за счет других. Получив больше материальных ресурсов, нежели остальные, великий князь низводит удельных князей до подчиненного положения и, тем самым, окончательно сводит на нет самовластие собственников земли, характерное для предыдущей эпохи. «Таким образом, крайнее развитие личного начала привело к водворению начала совершенно противоположного - начала государственного» [5, с. 336]. Для сохранения целостности вотчин вводится порядок перехода власти по праву первородства, что влечет за собой прекращение дроблений вотчины. Кроме этого, в обществе укрепляются христианские представления о божественной природе власти, вследствие чего князья начинают олицетворять собой высший порядок. Б.Н. Чичерин, отмечает, что четко обозначенной грани между государственным и догосударственным состоянием не существует, «но противоположные начала частного и публичного права проявляются с полной ясностью и дают возможность юридической оценки явлений».

Столь длительная эволюция социальной структуры находит свое завершение в правление Ивана IV, свидетельство этому Б.Н. Чичерин находит в духовной грамоте московского царя. Содержание этого документа свидетельствует о становлении единодержавия. Иван IV благословляет старящего сына царством Русским. Младшему же сыну Федору завещает несколько городов, но прибавляет, что они ему же, Ивану, «к великому государству». Углич становится последним городом в практике раздела территории государства на уделы и «царство русское составляет единое целое, в котором частный порядок наследования не может иметь место» $[5$, c. 260].

1. Чичерин Б.Н. Областные учреждения России в XVII веке.- М., 1856.

2. Чичерин Б.Н. Курс государственной науки. Ч. 2. Социология.1896.

3. Чичерин Б.Н. Общее государственное право [Текст] / Б. Н Чичерин; под редакцией и с предисловием В.Л. Томсинова. — М.: Зерцало, 2006.

4. Чичерин Б.Н. 0 народном представительстве. М., 1899.

5. Чичерин Б.Н. Опыты по истории русского права М., 1858.

6. Чичерин Б.Н. Собственность и государство.—-СПб.: Изд-во Рус. Христиан. гуманитар. акад., 2005

( В Волк-Леонович Станислав Олегович ( ejiwolf2006@rambler.ru ).

Журнал «Современная наука: актуальные проблемы теории и практики» 